\title{
Does the Internet make us lonely?
}

Axel Franzen

The Internet and its potential effects on society receive much attention in public discussions. Many discussants expect that the World Wide Web will enhance global trade of products and services and thus will increase economic wealth. However, social scientists are concerned with possible social side-effects of the Internet. Specifically, a recent experimental study by Robert Kraut et al. (1998) found that greater use of the Internet decreases communication within the family, diminishes the size of the subjects' local social networks, and increases feelings of loneliness and depression. This study sheds doubt on the generality of these findings. Results from a survey of 15842 Internet users and a control group of 1196 non-users conducted in Switzerland suggest that Internet use neither decreases respondents' network size nor the time spent with friends. The study also shows that electronic mail is widely used and has positive effects on people's social networks. The study uses many socio-demographic control variables and statistical methods to control for simultaneity.

\section{Introduction}

Social scientists are, of course, concerned with the social consequences of new technologies. Lately, the diffusion of Internet access in industrial societies has received a lot of public attention. The effects of the World Wide Web on society can hardly be exaggerated. The Internet is an extremely useful communication tool. It enhances the worldwide exchange of information, products, and services. It reduces the geographic distance of markets and therefore increases competition and economic wealth. Due to its perceived consequences, the creation of the Internet is often compared to the invention of the car or the Gutenberg printing technique. Since knowledge and information are quickly accessible through the net, many proponents support the spread of Internet access to schools, universities, and society in general.

However, some psychologists and sociologists do not share this general euphoria about the Internet. They suspect that the Internet might decrease people's social networks. There is an extensive amount of literature that emphasizes the importance of individuals'embeddedness into social networks for mental health (e.g. Kadushin, 1982, Umberson et al., 1996), career opportunities (e.g. Granovetter, 1973, 1974), social support (e.g. Wellman and Wortley, 1990, Campbell et al., 1986) and community involvement (e.g. Putnam, 1995). Thus, a reduction of social networks is most likely to be harmful to individuals as well as to the functioning of democratic society.

But how could the Internet make us more lonely? There are at least two basic reasons. First, the Internet accelerates a trend in modern societies that economists and sociologists (Lindenberg, 1986) refer to as privatization in consumption. In a nutshell the argument runs as follows: as individuals become more affluent they can afford to acquire goods for private consumption that formerly had to be shared with others. Thus, we do not need to share houses, apartments or cars with friends or family members because individuals can afford to have those goods solely for themselves. On the one hand, private goods as compared to shared goods reduce transaction costs and, therefore, increase individual utility. On the other hand, private consumption deprives individuals of face-to-face communication and social approval that goes hand in hand with coordinating the use of shared goods. 
To be sure, there are still many social relations and forms of communication involved in finding and buying private goods. However, in the future finding information and buying private goods could be done less via personal transactions and increasingly through the Internet. To find a bargain will not require the exchange of information with friends and relatives but rather a good search engine that provides all the details. Thus, in addition to a privatization in consumption, the Internet may contribute to a privatization in transactions. Goods will not be offered and bought personally at a store around the corner or in supermarkets anymore, but from any part of the world through the Internet. Hence, the Internet has the potential to further deprive individuals of social contacts such that the unintended consequences of social isolation and its implications cannot be excluded perse.

It should be noticed, however, that the Internet's potential for privatization of transactions is probably limited. Granovetter (1985), criticizing Williamson (1975), has emphasized the importance of social embeddedness for market transactions. DiMaggio and Louch (1998) provide empirical evidence that consumers rely more on personal networks for market transactions the more uncertain product quality or service performance is. This is most likely the case with durable goods that are bought infrequently such as houses or used cars. However, social embeddedness is less important in markets with recurrent transactions (e.g. books or CDs) since sellers have an incentive to be honest towards customers. In those markets the Internet probably fosters the privatization of transactions.

The second reason why the Internet can make us lonely is much simpler. Many new technologies, most of all television, create shifts in people's time allocation. The more time individuals spend in front of TV sets, the less time they have for communicating with family members and friends (Robinson, 1990). Putnam (1995) believes that Americans' increasing TV consumption is one major cause for his thesis that America's social capital is declining. As with TV, the Internet also causes a technological transformation of leisure. It is possible that the more time people spend surfing the net, the less they spend with friends, neighbours, and family members. Thus, in addition to the privatization of transactions, the individualization of leisure time might be a further source of increased social isolation.

However, there are also some reasons why the Internet might have beneficial effects on people's social involvement. First, it can contribute to an efficient use of time in many transactions of daily life. Thus, shopping through the net can save a lot of time, e.g., travelling time usually spent to get from store to store in search of the desired product. The transaction time saved can be allocated to the time spent with family members, friends, and colleagues. Secondly, for many professions (e.g. journalists, computer programmers) the Internet increases the feasibility of working from a home-based office. Hence, it might contribute to the reversal of the strict separation of work and living space known since industrialization. More time flexibility could also increase contacts within the social network. Last, but not least, the Internet is a very cost efficient communication tool and has some advantages in comparison with other ways of communication. Electronic mail is much faster than postal mail, and while phone conversations depend on the availability of two interaction partners at the same time, electronic mail does not require this synchronization.

To summarize, there are different theoretical expectations of the Internet's effects on the social involvement of its users. What the net effect will be is doubtless an empirical question. And, it is most likely one that will create much debate. So far the empirical evidence is still sparse and controversial. Many existing empirical studies use small and highly selective samples of special user groups (see Wellman et al., 1996). A valuable contribution is the study by Robert Kraut et al. (1998) who found evidence that the Internet leads to a decline in people's social involvement. The authors provided 169 individuals in 73 households with free Internet access and observed changes in their behaviour over a period of two years. Participants completed a pre-test questionnaire before they were given access to the Internet, and a follow-up questionnaire after 12 to 24 months. The study found that Internet use (measured in weekly hours spent with the Internet) reduced subjects' within-family communication, decreased subjects' number of friends, and increased their feelings of loneliness and depression. The authors argue that these effects occur because of 
shifts in time allocation. Internet users might substitute the time formerly devoted to friends for time spent on-line. Furthermore, they argue that contacts developed or maintained via the Internet by electronic mail lack the more involving quality of face-toface contacts. Thus, in their view, the possibilities of electronic mail do not help much to maintain or create a social network.

Although Kraut's etal. (1998) study is interesting, its findings are not beyond doubt. First of all, the study did not involve a control group. Hence, the drop in social involvement may be due to some other unmeasured social process. Secondly, the study consists only of a relatively small sample of 169 individuals. Furthermore, participants were not drawn at random, but were already partly active in community development projects. Thus, it might be a selective sample of people who were particularly socially active at the beginning of the experiment and who reduced their community involvement (and thereby their general social involvement) due to other events than the introduction of the Internet into their households. Thirdly, the study measures weekly use of the Internet but does not differentiate between time spent communicating with people and other Internet uses. Thus, the argument that electronic mailing is not helpful for face-to-face contacts is a mere conjecture and empirically not really validated.

Other studies are, on the other hand, overly optimistic with regard to the Internet's social consequences. For instance, Katz and Aspden (1997) found no differences with regard to community involvement of Internet users and non-users. Instead, the authors report that $14 \%$ of their surveyed Internet users even made new social contacts through electronic mail and chat groups. However, the usual limitations of cross-sectional survey research apply to their study. Causal inferences about the Internet's beneficial effects have to be tentative since the results might be due to self-selection of individuals into the user group.

The remainder of this article will present new results from an extensive survey recently conducted in Switzerland. Results of the study show, contrary to Kraut etal. (1998), that use of the Internet does not result in a decrease of users' social networks. Furthermore, the new findings suggest that the use of electronic mail might enlarge people's social involvement. The following section describes the design of the study and the data analysed; the results are then presented, and the final section summarizes and concludes with a discussion.

\section{Method and Data}

Part of the survey was conducted among the customers of Switzerland's largest Internet provider during March and April of 1998. At that time the provider had 76806 customers in the German speaking part of the country. ${ }^{1}$ All of them received an electronic mail message introducing the survey and asking for participation. The mail contained a link that led to the questionnaire which contained approximately 70 questions on aspects of Internet use and various socio-demographic variables (e.g. sex, age, income). Pre-tests showed that it took between 20 and 30 minutes to complete the questionnaire. After completion the questionnaire could be returned via the net and the data were stored in a database. To increase the response rate, a lottery was announced through which participants could win three cellular phones and a number of credit slips worth the equivalent of US $\$ 20$ to 80 . For that purpose subjects had to give their e-mail address which ensured that only customers of this specific provider were included in the study. In contrast to most other surveys done through the Internet, this ensured the calculation of the exact response rate. Two weeks after the first e-mail a reminder to participate was installed on the homepage of the provider and remained there throughout the data collection period. The questionnaire was returned by 15852 customers, which constitutes a response rate of about 20 per cent. This is a low response rate compared to surveys done via written questionnaires or telephone interviews. However, a comparison of the sample members with the age distribution of all customers, which is known by the provider, shows no significant deviations. The provider was also informed about the overall surfing time of its customers. The latter amounts to an average of 10.5 hours per month. In our sample the average surf time is 13 hours per month. Thus, our sample consists of a slightly more active group.

As a control group we randomly drew 2500 households from the German part of Switzerland 
Table 1 Means and standard deviations of network size, socio-demographic, and leisure-time use variables

\begin{tabular}{|c|c|c|c|c|}
\hline & \multicolumn{2}{|c|}{ Population sample } & \multicolumn{2}{|c|}{ Internet sample } \\
\hline & Mean & S.D. & Mean & S.D. \\
\hline Number of friends & 10.1 & 7.90 & 12.25 & 7.4 \\
\hline Age in years & 46.0 & 16.25 & 38.0 & 11.5 \\
\hline Gender $(0=$ male, $1=$ female $)$ & 0.48 & 0.50 & 0.11 & 0.32 \\
\hline Civil status $(0=$ unmarried $/ 1=$ married $)$ & 0.55 & 0.50 & 0.52 & 0.50 \\
\hline Size of household & 2.55 & 1.36 & 2.8 & 1.34 \\
\hline Monthly income per member & 2950 & 1788 & 3485 & 2031 \\
\hline Education (years) & 12.6 & 2.17 & 14.1 & 2.46 \\
\hline Sibsize & 2.62 & 2.11 & 1.97 & 1.54 \\
\hline $\begin{array}{l}\text { Place growing up } \\
(0=\text { village } / 1=\text { city })\end{array}$ & 0.32 & 0.47 & 0.39 & 0.49 \\
\hline Homework $(0=$ no $/ 1=$ yes $)$ & 0.30 & 0.46 & 0.53 & 0.50 \\
\hline Employee $(0=$ no $/ 1=$ yes $)$ & 0.47 & 0.50 & 0.63 & 0.48 \\
\hline Self employed $(0=$ no $/ 1=$ yes $)$ & 0.08 & 0.28 & 0.14 & 0.34 \\
\hline Time spent on sports (hours per week) & 2.08 & 3.43 & 2.61 & 3.56 \\
\hline Time reading (hours per week) & 1.74 & 3.04 & 1.92 & 3.30 \\
\hline $\begin{array}{c}\text { Time reading newspapers (hours per } \\
\text { week) }\end{array}$ & 2.85 & 3.22 & 3.31 & 3.35 \\
\hline Time spent with family (hours per week) & 11.67 & 18.20 & 9.80 & 14.10 \\
\hline Time spent going out (hours per week) & 2.20 & 3.60 & 3.12 & 4.50 \\
\hline Outdoor activity time (hours/week) & 2.28 & 3.88 & 1.47 & 3.29 \\
\hline TV watching time & & & & \\
\hline (minutes of day before interview) & 100.2 & 92.8 & 87.53 & 89.92 \\
\hline $\mathrm{N}$ & & 745 & & 13251 \\
\hline
\end{tabular}

Note: The reported numbers of cases deviate from the original sample sizes due to missing data in one or more of the listed variables. Question wording for the variables is shown in Table A2 of the Appendix. The variable 'homework' refers to whether respondents also work at home for their occupation.

who received an almost identical written questionnaire. ${ }^{2}$ Of these 1196 were completed and returned which constitutes a response rate of 50 per cent. ${ }^{3}$ Of the participants of the written questionnaire, 314 did use the Internet at least occasionally and were excluded from the study (we did not include detailed questions on Internet use in the control group). Comparison between sample distributions of age, education, respondents' sex, and size of households with the official statistical information available do not show any important deviations. Thus, overall the data basis embraces 16915 cases.

\section{Results}

The questionnaire provides three measures of social involvement. Participants were asked how many people they count as close friends, how much time they spent during the last week (prior to the interview) with friends, and whether they usually discuss personal problems with friends or not. The number of friends a person has comes closest to the indicator used by Kraut et al. (1998) ${ }^{4}$ as well as to those in many other studies on social involvement (Granovetter, 1973, Moore, 1990, see also Marsden, 1990). The average reported number of friends in the population sample is 10 and in the Internet sample $12 .{ }^{5}$ Empirical studies on network size are usually restricted to regressing the number of friends on a number of socio-demographic variables. Thus, Moore (1990) reports that the females in his study have larger networks than men, and that education and income are positively correlated with the number of friends. In addition to socio-demographic variables the first model presented includes also a number of variables that measure people's use of leisure time, such as the amount of time spent with the 
family, time spent on reading books and newspapers, and on sports or outdoor activities. The means and standard deviations of the variables used in the following models are reported in Table 1 for both samples.

Comparison of the means of the socio-demographic variables between the control group and the Internet sample (Table 1) reveals that the Internet users are a highly selected group of individuals. They are mostly males ( 89 per cent) with higher educational and professional qualifications than the average population. Thus, the finding that Internet users report on average a larger number of close friends might be due to their specific socioeconomic status. Controlling for the influence of these and other demographic variables is usually accomplished by regressing the number of friends on the variable of interest together with sociodemographic variables. The results of such an OLSRegression are presented in the first column of Table 2.

Since the distribution of the number of friends is skewed, the log transformation is used. Log transformations were also applied to most other continuous variables in order to take possible nonlinearity into account. Internet use is measured by a dummy variable that indicates whether respondents belong to the Internet group or to the control group. Non-users were coded as zero. As can be seen from the result for model 1 (Table 2), Internet users differ significantly from non-users with respect to their reported number of friends, even after controlling for many socio-demographic variables and other variables that measure respondents' use of leisure time. Thus, Internet users have 24 per cent more friends than non-users.

Most effects of the socio-demographic variables have the expected direction and replicate former findings (e.g. Moore, 1990). Thus, individuals with higher educational and economic status ${ }^{6}$ have more friends. Network size is also larger for people that are married (11 per cent), live in larger households, or have a larger number of siblings. However, the negative effects for gender and the number of children were not replicated. Both variables were therefore excluded from the model. Furthermore, people who spent more time with their families, on sport, or on other outdoor activities have more social contacts. In addition, it was found that people who grew up in a non-urban environment tend to have larger networks as well as individuals who work partly at home. All of these variables have small but significant effects on the number of friends. In sum, the results suggests that network size depends on individuals' occupational and leisure time activities. More active individuals tend to have larger networks.

The empirical result that Internet users have larger social networks does not necessarily suggest that the use of the Internet causes more social contacts. It is most likely the case that Internet users had more social contacts due to other unmeasured influences before they started to use the Internet. In any case the finding is of descriptive interest. Internet users are, on average, not socially isolated but on the contrary a relatively socially active group.

However, if Kraut et al. are correct then Internet users may start with a larger network but the network size should decrease over time. The questionnaire for the Internet sample included a question to discover in which month and year people started to use the Internet. This time variable ranges from 1 to 64 months. About half of the sample had used the Internet for more than 12 months and some users started more than 5 years ago. The hypothesis that network size decreases over time can be tested by regressing the time variable on network size. As can be seen from the results of this analysis (Table 2, column 2), there is no significant effect of the time (measured in months) that people have used the Internet on network size.

It was already mentioned that the Internet should have a twofold effect depending on how it is used. If people use it for shopping, information seeking, or entertainment it is expected that time is allocated away from socializing with others. However, using the Internet predominantly as a communication tool might have beneficial effects for social networks. This does not necessarily imply that communication via e-mail helps individuals to find new friends. But communication via the Internet might help users to keep their social network. Put differently, depriving Internet users of the communicative channel would lead to a decrease in network size over time. Thus, it is important to separate both effects. The questionnaire contains questions on how much time respondents spent on the Internet besides the time they use for e-mails. ${ }^{7}$ Additionally, they were asked 
Table 2. Determinants of participants (log) number of friends

\begin{tabular}{|c|c|c|c|c|}
\hline Models & $\begin{array}{l}(1) \\
\text { OLS }\end{array}$ & $\begin{array}{l}(2) \\
\text { OLS }\end{array}$ & $\begin{array}{l}(3) \\
\text { OLS }\end{array}$ & $\begin{array}{c}(4) \\
\text { Hausman test }\end{array}$ \\
\hline Constant & $\begin{array}{c}0.96 \\
(10.38)\end{array}$ & $\begin{array}{c}1.21 \\
(12.85)\end{array}$ & $\begin{array}{c}1.02 \\
(10.40)\end{array}$ & $\begin{array}{c}1.00 \\
(9.64)\end{array}$ \\
\hline Age in years $(\log )$ & $\begin{array}{c}0.13 \\
(5.52)\end{array}$ & $\begin{array}{c}0.13 \\
(4.84)\end{array}$ & $\begin{array}{c}0.16 \\
(6.18)\end{array}$ & $\begin{array}{c}0.17 \\
(6.21)\end{array}$ \\
\hline Married (0/1) & $\begin{array}{c}0.11 \\
(6.83)\end{array}$ & $\begin{array}{c}0.11 \\
(6.73)\end{array}$ & $\begin{array}{c}0.11 \\
(6.72)\end{array}$ & $\begin{array}{c}0.11 \\
(6.53)\end{array}$ \\
\hline Size of household & $\begin{array}{c}0.05 \\
(8.06)\end{array}$ & $\begin{array}{c}0.05 \\
(7.88)\end{array}$ & $\begin{array}{c}0.05 \\
(7.91)\end{array}$ & $\begin{array}{c}0.05 \\
(7.87)\end{array}$ \\
\hline Sibship size & $\begin{array}{c}0.01 \\
(2.90)\end{array}$ & $\begin{array}{c}0.01 \\
(2.38)\end{array}$ & $\begin{array}{c}0.01 \\
(2.21)\end{array}$ & $\begin{array}{c}0.01 \\
(2.30)\end{array}$ \\
\hline Income $(\log )$ & $\begin{array}{c}0.09 \\
(4.77)\end{array}$ & $\begin{array}{c}0.09 \\
(4.64)\end{array}$ & $\begin{array}{c}0.09 \\
(4.68)\end{array}$ & $\begin{array}{c}0.09 \\
(4.54)\end{array}$ \\
\hline Education (years) & $\begin{array}{c}0.01 \\
(5.64)\end{array}$ & $\begin{array}{c}0.01 \\
(5.20)\end{array}$ & $\begin{array}{c}0.01 \\
(4.32)\end{array}$ & $\begin{array}{c}0.01 \\
(4.21)\end{array}$ \\
\hline Place growing up (0/1) & $\begin{array}{l}-0.03 \\
(-2.84)\end{array}$ & $\begin{array}{l}-0.03 \\
(-2.57)\end{array}$ & $\begin{array}{l}-0.04 \\
(-2.98)\end{array}$ & $\begin{array}{c}-0.04 \\
(-3.02)\end{array}$ \\
\hline Homework (0/1) & $\begin{array}{c}0.04 \\
(3.15)\end{array}$ & $\begin{array}{c}0.05 \\
(3.66)\end{array}$ & $\begin{array}{c}0.04 \\
(2.83)\end{array}$ & $\begin{array}{c}0.04 \\
(2.84)\end{array}$ \\
\hline Employee $(0 / 1)$ & $\begin{array}{c}0.02 \\
(1.58)\end{array}$ & $\begin{array}{c}0.02 \\
(1.01)\end{array}$ & $\begin{array}{c}0.02 \\
(1.24)\end{array}$ & $\begin{array}{c}0.02 \\
(1.18)\end{array}$ \\
\hline Self employed (0/1) & $\begin{array}{c}0.06 \\
(2.83)\end{array}$ & $\begin{array}{c}0.05 \\
(2.30)\end{array}$ & $\begin{array}{c}0.07 \\
(3.14)\end{array}$ & $\begin{array}{c}0.07 \\
(3.12)\end{array}$ \\
\hline Time spent on sports (log) & $\begin{array}{c}0.06 \\
(8.90)\end{array}$ & $\begin{array}{c}0.06 \\
(8.57)\end{array}$ & $\begin{array}{c}0.05 \\
(6.99)\end{array}$ & $\begin{array}{c}0.05 \\
(6.63)\end{array}$ \\
\hline Reading time books (log) & $\begin{array}{c}0.01 \\
(1.28)\end{array}$ & $\begin{array}{c}0.01 \\
(1.66)\end{array}$ & $\begin{array}{l}0.01 \\
(1.11)\end{array}$ & $\begin{array}{l}0.01 \\
(1.17)\end{array}$ \\
\hline Reading time newspapers (log) & $\begin{array}{c}0.02 \\
(2.36)\end{array}$ & $\begin{array}{c}0.02 \\
(2.63)\end{array}$ & $\begin{array}{c}0.02 \\
(3.02)\end{array}$ & $\begin{array}{c}0.02 \\
(3.04)\end{array}$ \\
\hline Time spent with family (log) & $\begin{array}{c}0.02 \\
(4.91)\end{array}$ & $\begin{array}{c}0.02 \\
(4.83)\end{array}$ & $\begin{array}{c}0.02 \\
(4.84)\end{array}$ & $\begin{array}{c}0.02 \\
(4.84)\end{array}$ \\
\hline Time spent going out (log) & $\begin{array}{c}0.05 \\
(8.54)\end{array}$ & $\begin{array}{c}0.05 \\
(8.34)\end{array}$ & $\begin{array}{c}0.05 \\
(7.29)\end{array}$ & $\begin{array}{c}0.05 \\
(7.21)\end{array}$ \\
\hline Time spent outdoor activities (log) & $\begin{array}{c}0.02 \\
(2.68)\end{array}$ & $\begin{array}{c}0.02 \\
(3.41)\end{array}$ & $\begin{array}{c}0.02 \\
(2.81)\end{array}$ & $\begin{array}{c}0.02 \\
(2.75)\end{array}$ \\
\hline Time spent watching TV (log) & $\begin{array}{c}-0.01 \\
(-3.95)\end{array}$ & $\begin{array}{l}-0.01 \\
(-4.09)\end{array}$ & $\begin{array}{c}-0.01 \\
(-3.40)\end{array}$ & $\begin{array}{l}-0.01 \\
(-3.33)\end{array}$ \\
\hline Net-user no/yes $(0 / 1)$ & $\begin{array}{c}0.24 \\
(9.52)\end{array}$ & & & \\
\hline Time since on Internet (log of month) & & $\begin{array}{c}0.01 \\
(0.63)\end{array}$ & $\begin{array}{c}-0.01 \\
(-0.95)\end{array}$ & $\begin{array}{l}-0.01 \\
(-0.98)\end{array}$ \\
\hline Intensity of Internet use (log) & & & $\begin{array}{l}-0.05 \\
(-4.81)\end{array}$ & $\begin{array}{l}-0.05 \\
(-4.39)\end{array}$ \\
\hline Number of e-mail contacts $(\log )$ & & & $\begin{array}{c}0.13 \\
(16.11)\end{array}$ & $\begin{array}{c}0.14 \\
(5.77)\end{array}$ \\
\hline Standardized residual of mail contacts & & & & $\begin{array}{l}-0.01 \\
(-0.42)\end{array}$ \\
\hline $\mathrm{N}$ & 14095 & 12870 & 12213 & 12154 \\
\hline Adjusted $\mathrm{R}^{2}$ & 0.06 & 0.05 & 0.08 & 0.08 \\
\hline
\end{tabular}

Notes: Reported are the unstandardized regression coefficients. Numbers in brackets denote t-values. Independent variables are regressed on the log number of respondents' friends. (0/1) indicates dichotomous variables, and $(\log )$ logarithmic transformed variables.

Most variables are self explained. 'Place of growing up' refers to non-urban versus urban place respondents grew up, the variable 'homework' measures whether respondents also work at home for their jobs. 
with how many people they communicated through electronic mail for private purposes during the week prior to the study. The average number of people contacted via e-mail is four.

Model 2 can now be extended by adding both variables to the model. A negative sign is expected for the time spent on the Internet, but a positive sign for the variable that measured e-mail contacts. The results of the analysis are displayed in Table 2, column 3. The time people spent on the Internet is negatively correlated with the number of friends. The effect is not very strong but highly significant. Since we have logarithmically transformed variables, the effect can be interpreted as an elasticity. Thus, a 1 per cent increase in the time spent on the Internet leads to a reduction in the number of close friends by 0.05 per cent. The number of e-mail contacts, on the other hand, is positively correlated with the number of friends. A 1 per cent increase in e-mail contacts leads to an increase of the number of friends by 0.13 per cent. Therefore, this effect is small but also highly significant.

However, the results of model 3 leave us in doubt as to whether e-mail contacts determine network size for two distinct reasons. First, it might very well be the case that people have a given number of friends for reasons unmeasured by the model. This interpretation is supported by the low amount of explained variance which is, however, not unusual for models that explain network size (e.g. Moore, 1990). For convenience, let us call this unmeasured influence a person's social skill or ability to relate to others. Then the unmeasured social skill might determine both the number of friends and the extent to which people use the Internet for communication. Technically speaking, this interpretation assumes that the number of friends and the amount of e-mail contacts are both endogenous variables. Thus, it would be appropriate to specify a simultaneous equation model.

The second argument is that the social network determines the amount of e-mail contacts and not vice versa. This argument implies that no decrease in the network would be observed if users could no longer use the Internet for communicative purposes. There are statistical tests available to test the merit of the first argument. Unfortunately, there is no way to test the second argument with the data at hand. ${ }^{8}$
The first argument can be addressed, however. If the network size and e-mail contacts are both endogenous variables, the proper simultaneous specification can be written as

$$
\begin{gathered}
f_{i}=\beta_{1}+\beta_{2} S_{i}+\beta_{3} T_{i}+\beta_{4} m_{i}+u_{i} \\
m_{i}=\gamma_{1}+\gamma_{2} S_{i}+\gamma_{3} O_{i}+\gamma_{4} f_{i}+v_{i}
\end{gathered}
$$

where $f=$ number of friends;

$\mathrm{m}=$ number of e-mail contacts;

$S=$ a vector of socio-demographic variables;

$T=$ a vector of time use variables;

$O=$ a vector of other variables that predict

e-mail contacts;

$v, u=$ error terms.

In this model the number of friends depends on the number of e-mail contacts and the number of e-mail contacts depends, in turn, on the number of friends. If simultaneity is present, then the endogenous regressor $m$ is correlated with the error term $u$. In such a case a basic assumption of the OLS regression is violated and an alternative to OLS (e.g. two-stage least-square) must be applied for estimation. Whether simultaneity is present can be tested by the Hausman specification test (Gujarati, 1995, Greene, 1993). This test proceeds in two steps. First, the reduced form equation of (2) is specified by regressing $m$ on all exogenous variables of the equation system:

$$
m_{i}=\gamma_{1}+\gamma_{2} S_{i}+\gamma_{3} O_{i}+\gamma_{4} T_{i}+w_{i} .
$$

Let the error term of this regression be $w_{i}$ and the estimated error term $\omega_{i}$. Secondly, equation (1) is re-estimated and $\omega_{i}$ included as a regressor. If simultaneity is present, then the estimated error term $\omega_{i}$ will have a significant influence on $f$. The results of the estimation of equation (3) are presented in Table A1 of the Appendix; the results of the Hausman test are included in column 4 of Table 2 . As can be seen from the $\mathrm{t}$-value $(\mathrm{t}=-0.42), \omega_{i}$ is far from being significant. Thus, the hypothesis that simultaneity is present can be rejected. Hence, there is no indication that e-mail contacts and the number of friends are both jointly determined by any other unmeasured variable. Therefore, doubts about the causality of the model cannot be justified on the grounds that both variables are endogenous. ${ }^{?}$

The questionnaire also included a question concerning how much time respondents have spent 
Table 3 Determinants of (log) time spent with friends

\begin{tabular}{|c|c|c|}
\hline & OLS coefficient & T-value \\
\hline Constant & 2.40 & 17.49 \\
\hline Age in years (log) & -0.42 & -11.57 \\
\hline Gender $(0=$ male $/ 1=$ female $)$ & 0.09 & 3.26 \\
\hline Married $(0 / 1)$ & -0.09 & -3.79 \\
\hline Size of household & -0.04 & -4.47 \\
\hline Income (log) & 0.11 & 4.06 \\
\hline Education (years) & -0.01 & -3.00 \\
\hline Place growing up (0/1) & 0.07 & 4.10 \\
\hline Place of living $(0 / 1)$ & 0.05 & 2.91 \\
\hline Homework $(0 / 1)$ & 0.05 & 2.91 \\
\hline Work hours per week (log) & -0.02 & -2.49 \\
\hline No. of siblings & 0.00 & 0.30 \\
\hline Time spent on sports $(\log )$ & -0.01 & -1.45 \\
\hline Reading time books (log) & 0.04 & 4.17 \\
\hline Reading time newspapers (log) & 0.06 & 5.89 \\
\hline Time spent with family (log) & 0.06 & 9.04 \\
\hline Time spent going out (log) & 0.24 & 26.42 \\
\hline Time spent outdoor activities (log) & 0.03 & 2.52 \\
\hline Time spent watching TV (log) & -0.01 & -2.73 \\
\hline Time since on Internet (log of month) & -0.02 & -1.30 \\
\hline Intensity of Internet use (log) & -0.01 & -0.94 \\
\hline Number of e-mail contacts (log) & 0.12 & 10.11 \\
\hline $\mathrm{N}$ & 12414 & \\
\hline Adjusted $\mathrm{R}^{2}$ & 0.15 & \\
\hline
\end{tabular}

Notes: See the note to Table 2.

with friends during the week prior to answering the questionnaire. In the Internet sample the average amount of time spent with friends is 4 hours a week. In the control sample the average is 3.5 hours. Again, if the Internet has negative effects on personal communication, then it is expected that people who have used the Internet for a longer time or who use it more intensively should, on average, have spent less time with friends. The results of the analysis are reported in Table 3. Neither the amount of time people have used the Internet nor the time they usually spent in a week using the Internet reduces the time they socialize. However, there is again a positive effect for e-mail contacts. If the amount of e-mail contacts is increased by 1 per cent the time spent with friends increases by 0.12 per cent $(\mathrm{t}=10.11)$. Again, the Hausman specification test did not reveal simultaneity. ${ }^{10}$

The questionnaire contained an additional question which referred to the respondents' way of dealing with personal problems. About 20 per cent of all respondents answered that they usually do not discuss personal problems with their friends while all others do. Simple probit analyses as well as bivariate probit analyses render no significant effects for Internet users. Thus, both groups are equally likely to discuss personal problems with friends. People who do have e-mail contacts even have a slightly higher chance of personally discussing their problems. ${ }^{11}$

\section{Conclusions}

There are two reasons why the Internet might deprive people of social contacts. First, the Internet has the potential to substitute real social contacts that are usually present in economic transactions by virtual transactions. Hence, the Internet could boost what might be called the privatization of transactions. Secondly, as with any other activity, using the Internet is time-consuming. Hence, the Internet might change people's time allocation. The time that was formerly spent socializing might now be 
increasingly spent on the Internet. However, there are also reasons why the Internet might lead to more social contacts. First, the Internet is a very cost-efficient and fast communication tool and has advantages if compared to communication via telephone or postal mail. Secondly, using the Internet for shopping and information seeking might save time that can be used communicatively. Which of these influences will be most dominant is definitely an empirical question.

The major finding of the above analyses suggests that the Internet has no negative effects on people's social networks. Thus, respondents who have used the Internet for a longer time period have the same number of close friends and spent as much time socializing with them as people who have used the Internet only for a short period. Hence, this finding contradicts the results of former studies (e.g. Krautet al., 1998) who report that the Internet diminishes people's social network.

Furthermore, the intensity of Internet use was measured and separated into the time people spent on information seeking and other usage and the intensity with which the Internet is used for communication. First, the finding with respect to the intensity of non-communicative purposes is somewhat ambiguous. The more intensively respondents use the Internet, the smaller their social network tends to be. However, this effect is very small and is only found with respect to network size but not with respect to the time spent socializing with friends. Second, the more e-mail contacts an Internet user has, the larger his social network tends to be and the more time he spends socializing with others. Both effects are small, since a 1 per cent increase in private e-mail contacts leads to a 0.13 per cent increase in the number of close friends and to a 0.12 per cent increase in time spent with friends. The positive effects could be due to the fact that electronic mail is a fast and cost-efficient communicative tool. However, the finding is also consistent with an interpretation that turns the causality around. Thus, people might have more e-mail contacts because they have larger social networks. Or, the effect could be recursive such that large networks lead to more e-mail communication which, in turn, helps to maintain and enlarge social networks. But even if the results give no clear answer with respect to the effects of e-mail use they clearly refute the assumption that the Internet makes people lonely.

These are, of course, only preliminary results. So far the Internet is used by about 20 per cent of the population in Switzerland as well as in other European countries. Thus, we do not yet know what the long-term effect of the Internet will be when it has diffused further in society and when Internet shopping as well as other forms of use have become more common. The results of this study, however, indicate that the Internet has so far no harmful effects on people's social networks.

\section{Notes}

1. At that time, the provider's market share in Switzerland was slightly larger than 30 per cent.

2. The written questionnaire was a little shorter than the e-mail version, since we did not ask questions on aspects of Internet use.

3. 138 of the drawn addresses were invalid due to address changes and were thus excluded from the valid random sample. Random selection within the household was done via the 'birthday method'.

4. Kraut etal. (1998) measured social involvement by asking participants with how many people they socialized within the Pittsburgh area at least once a month.

5. In the studies by Moore (1990) or Marsden (1987) respondents had to mention their friends' names. This procedure usually results in a lower average number of friends (see also Campbell and Lee, 1991). In Moore (1990) the mean number of named friends is three. In our survey respondents simply had to write down the number of people they count as their close friends. The reported findings are congruent with Fischer (1982) and Wellman (1999).

6. Economic status is measured by household income per household member.

7. The net-users were asked how many days a week they typically use the Internet and how many minutes (or hours) they spent on-line during an ordinary day.

8. At first sight, it appears reasonable to check whether email contacts increase over time. This could be interpreted as an indication that people gain new e-mail contacts different from their original social network. However, the finding is also compatible with the interpretation that Internet use has diffused through the existing network. See also Maddala (1992) for a discussion of causality in econometrics. 
9. An equivalent discussion about causality also applies, of course, to the finding of a negative effect of the intensity of Internet use on the number of friends. However, the Hausman test of simultaneity also indicates the absence of simultaneity in this case.

10. It must be added that the model initially controlled for a possible interaction effect of the time period respondents have been Internet users and the intensity of Internet use during the week. However, the interaction effect has not been significant.

11. The detailed results are available from the author on request.

\section{Acknowledgement}

Support from the research grant 'Working conditions, work orientation and labor market participation' by the Swiss National Science Foundation is gratefully acknowledged.

\section{References}

Campbell, K. and B. Lee (1991) Name generators in surveys of personal networks. Social Networks, 13, 203-221.

Campbell, K., Marsden, P. V., and Hurlbert, J. S. (1986) Social resources and social economic status. Social Networks, 8, 97-117.

DiMaggio, P. and Louch, H. (1998) Socially embedded consumer transactions: for what kind of purchases do people most often use networks? A merican Sociological Review, 63, 619-637.

Fischer, C. S. (1982) To Dwell A mong Friends. University of Chicago Press, Chicago.

Granovetter, M. (1973) The strengths of weak ties. American Journal of Sociology, 73, 1361-1380.

Granovetter, M. (1974) Getting a Job: A Study of Contacts and Careers. Harvard University Press, Cambridge, Mass.

Granovetter, M. (1985) Economic action and social structure: the problem of embeddedness. American Journal of Sociology, 91, 481-501.

Greene, W. H. (1993) Econometric Analysis. Macmillan, New York.

Gujarati, D. N. (1995) Basic Econometrics. McGraw-Hill, New York.

Kadushin, C. (1982) Social density and metal health. In Marsden, P. V. and Lin, N. (eds) Social Structure and Network A nalysis. Sage, Beverly Hills, Calif, pp. 147158.
Katz, J. E. and Aspden, P. (1997) A nation of strangers? Communications of the ACM, 40, 81-86.

Kraut, R., Lundmark, V., Patterson, M., Kiesler, S., Mukopadhyay, T., and Scherlis, W. (1998) Internet paradox: a social technology that reduces social involvement and psychological well-being? American Psychologist, 53, 1017-1031.

Lindenberg, S. (1986) The paradox of privatization in consumption. In Diekmann, A. and Mitter, P. (eds) Paradoxical Effects of Social Behavior. Physica Verlag, Heidelberg, pp. 297-310.

Maddala, G. S. (1992) Introduction to Econometrics, 2nd edn. Macmillan, New York.

Marsden, P. V. (1990) Network data and measurement. Annual Review of Sociology, 16, 435-463.

Moore, G. (1990) Structural determinants of men's and women's personal networks. American Sociological Review, 55, 726-735.

Putnam, R. D. (1995) Bowling alone: America's declining social capital. Journal of Democracy, 6, 65-78.

Robinson, J. P. (1990) Television's effects on families' use of time. In Bryant, J. (ed.) Television and the American Family. Erlbaum, Hillsdale, NJ, pp. 195-209.

Umberson, D, Chen, M. D., House, J. S., Hopkins, K., and Slaten, E. (1996) The effect of social relationships on psychological well-being: are men and women really so different? American Sociological Review, 61, 837-856.

Wellman, B. (1999) Networks in the Global Village. Westview Press, Boulder, Colo.

Wellman, B. and Wortley, S. (1990) Different strokes from different folks: community ties and social support. A merican Journal of Sociology, 96, 558-588.

Wellman, B., Salaff, J., Dimitrova, D., Carton, L., Gulia, M., and Haythornthwaite, C. (1996) Computer networks as social networks: collaborative work, telework, and virtual community. Annual Review of Sociology, 22, 213-238.

Williamson, O. (1975) Markets and Hierarchies. New York, Free Press.

\section{Author's Address}

Institute for Sociology, University of Berne, Lerchenweg 36, 3012 Berne, Switzerland. Tel.: +31 631 4874; fax: +31 631 4817; e-mail: axel.franzen@soz.unibe.ch.

Manuscript received: May 1999. 
Table A1. Determinants of participants (log) number of e-mail contacts

OLS coefficient

\section{Constant}

Age in years $(\log )$

Married (0/1)

Size of household

Income (log)

Education (years)

Place growing up (0/1)

Homework $(0 / 1)$

Employee (0/1)

Self employed (0/1)

Sibship size

Time spent on sports (log)

Reading time books (log)

Reading time newspapers (log)

Time spent with family (log)

Time spent going out (log)

Time spent outdoor activities (log)

Time spent watching TV (log)

Time since on Internet (log of month)

Intensity of Internet use (log)

Working hours per week (log)

Internet use for occupation $(0 / 1)$

Internet access at working place $(0 / 1)$

Meeting person through Internet $(0 / 1)$

PC at home (0/1)

E-mail for private purpose $(0 / 1)$ $\mathrm{N}$

Adjusted $\mathrm{R}^{2}$
0.61

$-0.22$

0.03

0.02

0.13

0.01

0.04

0.04

$-0.03$

$-0.01$

0.00

0.06

0.03

$-0.01$

0.01

0.04

0.03

$-0.01$

0.09

0.18

$-0.01$

0.07

0.07

0.38

0.10

0.49

12573

0.21
T-value

5.72

$-8.05$

1.50

3.17

6.48

4.95

3.00

2.56

$-1.44$

$-0.63$

0.04

9.40

3.48

$-1.67$

1.27

5.29

4.19

$-3.53$

10.34

18.53

$-2.23$

5.24

7.59

23.13

3.01

30.31

Note: See Table A2 for the question wording of variables. 
Table A2. Question wording of variables

\section{Variable}

Age

Gender

Married

Size of household

Income

Education

Place growing up

Place of residence

Homework

Work hours per week

No. of siblings

Time spent on sports

Reading time books

Reading time newspapers

Time spent with friends

Time spent with family

Time spent going out

Time spent outdoor activities

Time spent watching TV

Time since on Internet

Intensity of Internet use

Number of E-mail contacts

Number of friends

Discussion of personal problems

Internet use for occupation

Internet access at working place

Meeting person through Internet

$\mathrm{PC}$ at home

E-mail for private purpose

\section{Question wording}

What is your year of birth?

What is your gender?

What is your marital status?

How many people live in your household, including yourself?

What is the sum of the monthly income of all household members?

What is your highest educational qualification?

Where did you grow up?

Where do you live?

Do you also work at home when working for your job?

How many hours do you usually work during a week?

How many siblings do you have?

How many hours did you spend last week on doing sports?

How many hours did you spend last week reading books?

How many hours did you spend last week reading newspapers?

How many hours did you spend last week meeting friends?

How many hours did you spend last week with family members?

How many hours did you spend last week going out?

How many hours did you spend last week going for outdoor activities?

How many hours and minutes did you spend watching TV yesterday?

When did you start to use the Internet regularly?

(a) How many days a week do you use the Internet?

(b) when using the Internet how many minutes/hours do you spend using it?

With how many people did you exchange e-mail for private purposes last week?

How many people would you say are close friends of yours?

Do you discuss personal problems with friends personally?

For which purpose do you mainly use the Internet?

Where do you have access to the Internet?

Have you ever personally met a person you got to know through the Internet?

Where do you have access to a computer?

Are you using e-mail mainly for occupational or private purposes? 